\title{
Abuso de bebida alcoólica e sua relação no contexto familiar
}

\author{
Ana Patrícia Araújo Torquato Lopes \\ Gabriela Schiavon Ganassin \\ Sonia Silva Marcon \\ Maria das Neves Decesaro \\ Universidade Estadual de Maringá
}

\begin{abstract}
Resumo
O objetivo do estudo foi apreender aspectos da vivência e do contexto familiar da pessoa consumidora de bebida alcoólica que não está em tratamento. Estudo descritivo exploratório, com abordagem qualitativa desenvolvido no Noroeste do Paraná. Foram entrevistados 11 sujeitos: seis usuários de álcool e cinco familiares. O uso nocivo do álcool foi identificado a partir do Alcohol Use Disorder Identification Test. A coleta de dados ocorreu mediante entrevista semiestruturada, gravada e transcrita para a realização da análise de conteúdo. Os resultados mostram sofrimento das famílias e usuários devido ao abuso de bebida alcoólica e características da convivência em família como violência e fragilidade dos laços familiares. Nota-se afastamento do convívio social, na tentativa da preservação da família e adaptação a uma situação provocada pelo membro dependente. Apesar dos aspectos negativos que prevalecerem, foi possível perceber que a família mantém esperança de cura e sobriedade, além da reinserção do usuário na dinâmica familiar e social.
\end{abstract}

Palavras-chave: abuso de álcool; alcoolismo; relações familiares.

\begin{abstract}
Alcoholic beverage abuse and its relationship in the family context. The study aims understanding experience's aspects and the family context of the alcohol consumer who is not under treatment. Descriptive study with a qualitative approach developed in the Northwest of Paraná. 11 individuals were interviewed, six alcohol users and five family members. The harmful use of alcohol was identified from the Alcohol Use Disorders Identification Test. The data were collected by semi-structured interviews, recorded and transcribed for conducting content analysis. Results show users and family suffering due to abuse of alcohol and family acquaintanceship characteristics such as violence and fragility of family ties. It has been noticed distance from social, in an attempt to preserve the family and adapting to a situation caused by the dependent member. Despite the negative aspects prevailing, it was revealed that the family keeps hope of healing and sobriety, in addition to the reintegration of the user in social and family dynamics.
\end{abstract}

Keywords: alcohol abuse; alcoholism; family relations.

\section{Resumen}

Abuso de bebida alcohólica y su relación en el contexto familiar. El objetivo del estudio era comprender los aspectos de la experiencia y el contexto de la familia de la persona que consume el alcohol que no es en el tratamiento. Estudio descriptivo con abordaje cualitativo desarrollado en el noroeste de Paraná. Entrevistamos a 11 sujetos, seis usuarios de alcohol y cinco miembros de la familia. El uso nocivo del alcohol se identificó a partir de la Prueba de Identificación de Trastornos Derivados del Alcohol. Los datos fueron coleccionados a través de entrevistas semi-estructuradas, grabadas y transcritas para la realización de análisis de contenido. Los resultados muestran que sufren los usuarios de las familias debido al abuso de alcohol y las características de la vida familiar como la violencia y la fragilidad de los lazos familiares. Nota para la retirada de sociales, en un intento de preservar la familia y la adaptación a una situación causada por el miembro dependiente. Aunque de los aspectos negativos prevalecen, se reveló que la familia mantiene la esperanza de la curación y la sobriedad, y la reintegración de los usuarios en la dinámica social y familiar.

Palabras clave: abuso de alcohol; alcoholismo; relaciones familiares. 
$\mathrm{O}$ consumo de bebidas alcoólicas é uma conduta adaptada à maioria das culturas. Seu uso está arrolado com festividades, ocasiões sociais e de negócios, cerimônias religiosas e eventos culturais. No entanto, o uso irregular e frequente do álcool é considerado um problema de saúde pública, por ser mundialmente a droga mais utilizada, legalmente comercializada e incentivada pela sociedade, e principalmente por ser um dos fatores de risco predominantes para as doenças crônicas não transmissíveis (DCNT) (Brasil, 2011).

Na Classificação Internacional de Doenças - CID-10 [Organização Mundial da Saúde (OMS), 2008], o termo "uso nocivo" é utilizado como aquele, feito de forma excessiva, que resulta em dano físico ou mental. No Manual de Diagnóstico e Estatístico de Transtornos Mentais - DSM IV [American Psychiatric Association (APA), 2011], utiliza-se o termo "abuso", definindo de forma mais precisa, pois são considerados também consequências sociais do uso problemático da bebida alcoólica, a ausência de compulsividade e fenômenos como tolerância e crises de abstinência.

Uso abusivo ou nocivo do álcool para a pessoa é definido quando ocorrem recidivas dos seguintes problemas nos últimos 12 meses: incapacidade de cumprir as obrigações; abuso de álcool em situações que exigem atenção, habilidade e coordenação motora; litígios legais relacionados com o álcool; problemas de relacionamento interpessoal/social, causados ou exacerbados pelo álcool (Berenzon, Rebeca, Geofrey, \& Medina-Mora, 2011).

Esse consumo prejudicial resultou mundialmente, em 2010, na morte de 2,5 milhões de pessoas, incluindo desde violência, suicídio e acidentes de trânsito, até doenças de limitação da condição funcional, tais como, cirrose, pancreatite, demência, polineuropatia, miocardite, desnutrição, hipertensão arterial, infarto e câncer [World Heath Organization, (WHO), 2011].

Calcula-se que, mundialmente, o consumo de álcool pelo ser humano esteja relacionado a 3,2\% das mortalidades e 4,0\% das Disabilities Adjusted Life Year (DALY), onde no Brasil, o álcool é o fator de risco que mais contribui para a carga de doenças, sendo responsável por 6,2\% das doenças de limitação da condição funcional (WHO, 2011). Além disso, entre os anos de 2003-2005, o consumo médio por ano de álcool puro foi de 9,2 litros por pessoa com 15 anos ou mais, sendo 3,07 litros a mais que o consumo mundial médio anual, que foi de 6,13 litros em 2005 (WHO, 2011).

O consumo de bebida alcoólica pode provocar dependência e os transtornos, que são decorrentes do uso irregular e abusivo, atingem negativamente os familiares e contribuem massivamente para a violência doméstica, conflitos interpessoais, separação do casal, negligência infantil, dificuldades financeiras e legais e problemas clínicos (Malbergier, Cardoso, \& Amaral, 2012).

A pessoa consumidora nociva de bebida alcoólica não se reconhece como doente/dependente, assim como sua família também, pelo sofrimento, vergonha, medo do estigma, até por não considerar o alcoolismo uma doença, buscam ocultar essa situação, dificultando o tratamento e a reintegração da pessoa na sociedade (Goto, Couto, \& Bastos, 2013).
Apesar das facilidades de acesso aos grupos de apoio, a estigmatização do uso de álcool apresenta uma considerável barreira aos esforços dos profissionais da saúde em estreitar o vão entre o tratamento necessário aos dependentes e os serviços disponíveis para tal. Aderir ao tratamento pode desencadear aversão ao estigma, devido, principalmente, aos efeitos nocivos potenciais no trabalho e as atitudes negativas dos vizinhos e sociedade. E ainda, esta conveniência na negação pode estar intimamente ligada ao subconsciente do não querer a rotulação de "ser um alcoólatra" ou "dependente de álcool", onde reprimir a real situação é melhor do que encará-la e vivenciá-la autenticamente (Pimenta, 2010; Williamson, 2012).

No sentido de haver um maior enriquecimento crítico, pessoal e profissional, buscando implementar os interesses governamentais em trabalhar com as doenças crônicas, pelas consequências e gastos públicos e privados decorrentes do uso/abuso ou dependência de álcool, o estudo objetivou apreender aspectos da vivência e do contexto familiar da pessoa consumidora de bebida alcoólica que não está em tratamento.

\section{Metodologia}

Trata-se de um estudo descritivo exploratório com abordagem qualitativa, desenvolvido em uma cidade do Noroeste do Paraná, realizado junto a usuários de álcool e familiares.

Para localização dos informantes, primeiramente foi identificado, por intermédio da Prefeitura Municipal de Maringá - Secretaria da Fazenda, os estabelecimentos comerciais que vendem bebidas alcoólicas em um bairro específico de Maringá com registro comercial de 50 estabelecimentos. O bairro foi escolhido por nele estar localizado a irmandade Alcoólicos Anônimos (AA). Posteriormente foram escolhidos aleatoriamente e por conveniência três estabelecimentos comerciais dentre os que atendiam aos seguintes critérios: atendimento ao público nos três períodos do dia (manhã, tarde e noite) e nos sete dias da semana.

Os dados foram coletados no período de Junho a Agosto de 2013 em duas etapas. A primeira foi junto aos usuários de álcool e a segunda com o usuário e um familiar indicado por ele. Na primeira etapa cada um dos três estabelecimentos comerciais foi visitado por três dias e nos três períodos do dia de modo que a população a ser abordada fosse a mais diversificada possível.

Os frequentadores que se encontravam no estabelecimento durante o período destinado à coleta de dados (cerca de duas a quatro horas por período) foram abordados e convidados a participarem da pesquisa, sendo-lhes informado o objetivo do estudo e o tipo de participação desejada. Os dados foram coletados no próprio estabelecimento, tomando-se o cuidado de afastar-se dos demais presentes e certificando que o entrevistado estava apto e consciente para participar do questionário; esta aptidão foi percebida pelos próprios entrevistadores, que avaliaram o nível de consciência no ato da abordagem, observando se o participante fazia esforço 
para manter o diálogo e levar a entrevista a termo, ou se o paciente chega mesmo a cochilar, adormecer no curso da entrevista. O instrumento utilizado nesta etapa foi o Alcohol Use Disorder Identification Test - AUDIT, já validado no Brasil e desenvolvido pela OMS para levantamento, avaliação e classificação do hábito de consumo de bebidas alcoólicas no último ano (Pires \& Corradi-Webster, 2011).

O AUDIT é composto por 10 itens, sua aplicação produz escores que podem variar de 0-40, sendo que escores de 0-7 pontos indicam baixo risco de consumo abusivo; 8-15 pontos que indicam uso com risco; $16-19$ pontos indicam uso nocivo; e 20-40 pontos indicam que já apresentam sintomas da Síndrome da Dependência do Álcool (SDA). A partir da identificação da zona de risco, é possível ao profissional oferecer orientações personalizadas, focadas no padrão de consumo individual (Pires \& Corradi-Webster, 2011). Além do AUDIT, também foi aplicado um instrumento para levantar dados sociodemográficos (nível socioeconômico, religião, a existência, ou não, de familiar e telefone/endereço para contato). Neste momento, solicitou-se a assinatura do Termo de Consentimento Livre Esclarecido.

Para a segunda etapa da coleta de dados, foram identificados os indivíduos classificados pelo AUDIT como tendo consumo abusivo ou sintomas da SDA e que atendiam aos seguintes critérios de inclusão: ter família e ser morador do município de Maringá. Na sequência foi realizado contato telefônico com os usuários selecionados para obter autorização para realizar entrevistas aprofundadas com os mesmos e com seus familiares.

Dos 117 indivíduos que participaram da primeira etapa da coleta de dados, 36 estavam aptos para a segunda etapa e todos foram contatados, porém, apenas seis aceitaram envolver a família nas entrevistas. Contudo, um dos familiares se recusou a participar, de modo que 11 pessoas foram entrevistadas na segunda etapa, sendo seis usuários e cinco familiares.

As entrevistas foram previamente agendadas, e realizadas nos domicílios em ambiente preservado e em dias e horários diversos para usuários e familiares. Por ocasião da entrevista os participantes foram informados sobre os objetivos do estudo, sobre a livre opção em participar ou não, a possibilidade de negar a autorização em qualquer momento que desejasse, inclusive após o início da entrevista, e sobre o compromisso em garantir o anonimato das informações. Após o esclarecimento de dúvidas, os que concordaram em participar da pesquisa, o usuário de bebida alcoólica e o membro familiar assinavam o TCLE.

As entrevistas guiadas por perguntas norteadoras que abordavam assuntos de comportamento frente ao consumo, consequência de uso prolongado do álcool e relações familiares, tanto para os familiares quanto para os consumidores de bebida alcoólica, foram gravadas. Elas tinham duração média de 15 a 20 minutos, sendo posteriormente transcritas integralmente. Antes e depois das gravações, ocorriam conversas informais que também auxiliaram na construção e análise do estudo.
Para tratamento e categorização dos resultados foram utilizados os preceitos metodológicos de análise de conteúdo modalidade temática, que possibilita obter, por procedimentos sistemáticos e objetivos de descrição do conteúdo das mensagens, a inferência de conhecimentos relativos às condições de produção e recepção dessas informações (Bardin, 2011). A discussão dos resultados sustentou-se nos referenciais teóricos disponíveis na área da saúde e afins.

O estudo foi desenvolvido em consonância com as diretrizes disciplinadas pela Resolução 466/12 do Ministério da Saúde, seu projeto foi aprovado pelo Comitê Permanente de Ética em Pesquisa com Seres Humanos da Universidade Estadual de Maringá (Parecer $\mathrm{n}^{\mathrm{o}}$ 303.616/2013). Todos os participantes assinaram o termo de Consentimento Livre e Esclarecido em duas vias e para garantir o anonimato, foram identificados com a letra "A" para usuário de bebida alcoólica e letra "F" para o familiar, seguido pelo o número da ordem das entrevistas.

\section{Resultados e discussão}

Os 117 indivíduos que responderam o AUDIT tinham em média 48 anos, renda de cinco salários mínimos e dois filhos. Destes, 14 (12\%) foram classificados com baixo risco de consumo abusivo, 49 (42\%) com consumo de risco, 23 (20\%) com consumo abusivo e 31 (26\%) com sintomas da SDA. Observa-se, portanto, que quase metade dos entrevistados (46\%) consome bebidas alcoólicas de forma nociva e/ou já com sintomas de SDA.

$\mathrm{Na}$ análise dos relatos dos 11 entrevistados (seis usuários de bebida alcoólica e cinco familiares) foram identificadas duas categorias temáticas: (1) bebida alcoólica: dependência, comportamento e sentimentos; e, (2) consequências do consumo de bebida alcoólica.

Bebida alcoólica: dependência, comportamento e sentimentos. A família é parte integrante de qualquer indivíduo. Todos nascem em uma família que pode ter tantos aspectos em comum, como diferenças. Mesmo não sendo o único, o seio familiar é um ambiente de acesso constante, em que ocorrem interações, conflitos e interferências entre os seus integrantes.

Assim, a família é a base ética e moral, facilitando um processo de desenvolvimento pessoal que reflete nos atos e caminhos trilhados pelos filhos, estes conscientes do trajeto (Silva \& Guimarães, 2007).

Já para Levisky (1998), a família só concede essa proteção, a criança, por um determinado tempo, onde os elementos sociais constituem função marcante no crescimento, nas escolhas e na personalidade do ser.

Destarte, Dessen (2010) refere que familiares são aqueles com os quais se mantém uma ligação baseada na convivência e nas relações intergeracionais, portanto, todos os membros dessa associação são ativos, influenciando entre si de forma mútua e bidirecional. No qual estudar a família, envolve todos os transcursos de comunicação, relações e interações existentes. 
Nesta perspectiva, o sistema familiar vulnerável (membro(s) em situações de uso de drogas, violência ou outro que impeça o desenvolvimento saudável do grupo) reage de maneira ineficaz, sua composição de rede social e afetivo não são mais acionadas funcionalmente, falhando na promoção de resiliência e superação. Assim, o consumo abusivo de álcool por um de seus membros cria uma crise na interação familiar com a comunidade e com a sociedade (Prato, Couto, \& Koller, 2009).

O uso da bebida alcoólica pode ser mascarado pelo sentimento de negação, tanto pelo usuário quanto pelo familiar:

Tranquilo [...] sempre foi assim desde que a gente casou [...] e eu não tenho problema porque toda vida ele foi assim [...] (pausa) é uma coisa que a gente convive com isso, sabe conviver, sem causar atritos[...]. Então não tem problema [...] (F01 - esposa).

"Eu sempre separo na minha vida o trabalho da cachaça, do álcool [...] então sei separar o horário que devo começar e horário que eu devo parar" (A01).

[...] eu não gasto dinheiro com bebida alcoólica, não tenho coragem de gastar, uma que eu não gosto de bebida alcoólica, eu tomo por tomar às vezes. [...] Eu acho que como eu não tenho vício... na verdade eu não gosto. Bebo às vezes pela companhia não é? Por beber... porque às vezes ficar num lugar sem tomar nada é chato também sabe (A05).

Os relatos revelam que o uso abusivo/nocivo do álcool passa por uma longa fase até que familiares e usuários o reconheçam como problema, o negam como uma doença ou como algo que tenha ligação às dificuldades diárias enfrentadas. Ambos buscam justificativas para os conflitos no lar e para o próprio consumo.

A aceitação e banalização do consumo do álcool se dão por se tratar de uma droga de fácil acesso, legalizada, e aceita na sociedade, estando incluso em várias festividades como bailes, casamentos, formaturas, aniversários, réveillon, festas open bar, corroborando o consentimento social do seu consumo (Monteiro, Dourado, Graça, \& Freire, 2011).

Estudo realizado na Universidade Federal de São Carlos buscou compreender a vivência de familiares que frequentam o grupo de apoio Al-Anon diante da experiência do alcoolismo, e constatou que as atitudes do membro consumidor de álcool estão associadas a sentimentos e comportamentos que envolvem todo o grupo familiar como negação, segredo, culpa e vergonha, além da perda do respeito dentro do lar e o sofrimento profundo diante das dificuldades (Filzola, Tagliaferro, Andrade, Pavarini, \& Ferreira, 2009).

O enfrentamento da doença - alcoolismo - é longo, e inicialmente a família e o usuário percebem o uso do álcool como um fator de interação social, negando qualquer problema quanto ao abuso da substância ou como doença (Filzola et al., 2009).

Quando questionados sobre o que ocorre depois do consumo de bebida alcoólica, os relatos dos usuários refletem diferenças de percepção:
"Eu acho que eu fico de boa, mais sociável depois que bebo um pouquinho" (A01).

"Legal. Fico normal, não fico chato" (A03).

"Normal não né? Bêbado, mas não da alteração, não altera meu comportamento" (A04).

(Risos) Eu mudo de personalidade, por exemplo, coisa que eu nunca teria coragem de fazer sóbria, quando eu bebo, meu Deus! A vida é [...] complicado né? Muda assim [...] Eu fico mais contente, mais assim, dá mais coragem, de fazer as coisas (A05).

[...] quando a cachaça está na cabeça, a gente se sente grande, a gente se sente valente, forte, corajoso. Dá mais coragem, você cria coragem para muitas coisas que de repente você não teria vontade de falar, sem tá alcoolizado, você acaba falando, acaba também falando coisas que não deve. [...] você enriquece, fica rico, as vezes você tá sem um centavo para tomar uma cachaça, mas ali, nossa, você é o poderoso [...] (A02).

"Geralmente depois que bebo à noite, eu vou pra casa, chego em casa, descanso um pouco, esquento a minha janta, tomo banho e vou dormir. Não muda nada" (A06).

Enquanto que A1, A3, A4 e A6 negam mudanças de comportamento, A2 e A5 reconhecem que mudam quando estão sob o efeito do álcool, sendo que A5 refere ficar mais eufórico ou relaxado e A2 relata sentir-se corajoso e poderoso. A negação de mudanças de comportamento pode ser devido ao ambiente de interação social que o usuário de álcool está inserido, em que todos fazem o uso da bebida alcoólica, podendo levar o sujeito a não conseguir enxergar a existência de oscilações de humor e conduta.

Sob o efeito do álcool, o indivíduo pode apresentar fala arrastada, descoordenação motora, diminuição da capacidade de julgamento, aumento da autoconfiança, desinibição e euforia. Em contrapartida, o humor por sua vez pode ficar retraído, descontraído ou até mesmo agressivo (Monteiro et al., 2011).

Pesquisa realizada entre universitários mostra que o consumidor de bebida alcoólica apresenta altos percentuais de expectativas positivas quanto ao uso, tais como facilitação das interações sociais, diminuição de emoções negativas, ativação do prazer sexual, efeitos positivos no humor e na avaliação de si mesmo (Vargas, 2011). Por outro lado, estudo domiciliar de base populacional realizado na região metropolitana de São Paulo encontrou sentimentos negativos como tristeza, solidão e situações de risco associados a situações de ingestão de álcool (Cavarini, Oliveira, Kerr-Correa, \& Lima, 2012).

$\mathrm{Na}$ conversa informal antes e após a gravação das entrevistas alguns consumidores de bebida alcoólica fizeram referência às orientações recebidas e as estratégias utilizadas para abordagem da problemática do uso de álcool pelo Centro de Atenção Psicossocial para Álcool e Drogas (CAPSad), visto já terem sido atendidos neste serviço. E foram justamente e somente estes que reconheceram diferenças no seu comportamento após o uso do álcool. Este fato mostra que a aceitação da condição após o uso da bebida alcoólica talvez tenha 
se dado por terem recebido acompanhamento profissional em algum período da vida e assim, compreender que o que vivencia é um problema de saúde.

O uso de bebida alcoólica é uma problemática de extensa propagação por ser interpretado, nos dias atuais, com a finalidade de sociabilização e de facilitador de relações interpessoais. Suas implicações não estão restritas ao indivíduo consumidor deálcool, afeta as relações sociais, oâmbitofamiliarea sociedade (Moretti-Pires, Ferro, Büchele, Oliveira, \& Gonçalves, 2011).

Por ser o álcool uma ferramenta de interação social, os relatos mostram que embora o sujeito considere que seu consumo é nocivo, isto não é suficiente para ele modificar seu comportamento. Com o passar do tempo, os familiares são os primeiros a perceberem que um de seus integrantes sofre os efeitos negativos do consumo de bebida alcoólica.

Antes eu brigava muito, que eu ficava chamando a atenção dele, mas agora eu evito para não ter brigas entre nós dois você entendeu? Porque meu filho já ficou um ano de mal de mim por esse motivo. Então eu evito [...] Ele nunca aceita que bebeu demais e vive bebendo direto. Eu nunca vejo meu filho sem uma lata de cerveja na mão. E ele fica assim (pausa) [...] só lamentando, reclamando da vida, nunca está contente. E ele é muito ignorante, tudo o que você vai falar ele já fica agressivo, te responde mal, sai, deixa você falando sozinho [...] (F03-mãe).

[...] família nenhuma apoia o alcoolismo dele [...] Entre nós, é briga, né? Não tem o que discutir, não tem outro jeito, eu não sou sangue de barata, ele fala demais e eu tenho que dar um jeito de resolver o problema (F02-esposa).

Entretanto, após um tempo o usuário passa a notar diferenças no convívio familiar relacionado ao seu consumo de bebida alcoólica:

[...] fico irritado, não tenho paciência pra nada, qualquer coisinha é motivo pra eu discutir [...] Fica um negócio chato [...] a mulher mesmo (pausa) perde toda a vontade de sair, ir a algum lugar comigo. [...] ela sabe que eu enchendo a cara, bebendo cachaça, eu vou acabar aprontando. (pausa) Eles têm vergonha, desprezo, tudo isso (A02).

“[...] Quando eu extrapolo um pouco a mais assim, ela não fala nada, quieta, quieta. Agora se falar alguma coisa a gente acaba discutindo [...]" (A06).

As falas, principalmente dos familiares, demonstram que o consumidor é ignorado após um tempo de convívio e de brigas constantes, talvez devido a uma resposta às tentativas para cessar as discussões, ou na busca do não querer mais se magoar com o assunto. Já os indivíduos que consomem bebida alcoólica demonstraram reconhecer que houve mudanças em seu ambiente familiar, no entanto, por mais que percebam, não expressam reação de arrependimento ou culpa. A palavra "brigas" foi uma constante nos discursos, tanto de familiares quanto de consumidores. Isso caracteriza a existência de relações com agressividade e irritabilidade.
Há dificuldade em manter as relações familiares pacíficas e afetuosas, deixando que sentimentos de raiva e frustração se aflorem, fragilizando as relações que antes eram consideradas sólidas, conduzindo às discussões, brigas, agressividade e afastamento social e do grupo familiar. A sobrecarga que o a bebida alcoólica acarreta para a família atinge várias dimensões, inclui prejuízos na sociabilidade, no cotidiano, no lazer e no bem-estar físico e emocional (Santos, Silva, \& Silva, 2012).

O abalo emocional e físico que afeta as relações marcadas pela dependência alcoólica atinge a família, que perde o respeito pelo seu membro; a sociedade passa a encará-lo de maneira preconceituosa e o próprio sujeito, visto que sua força física se esvai, entrega-se ao vício, tornando-se incapaz de cuidar de si e de sua família. Com isso, a família deixa de reconhecê-lo como provedor ou membro principal e o desapropria dos cargos de responsabilidade que lhe eram confiados, afetando a qualidade de vida do grupo familiar (Filzola et al., 2009).

Dessa forma, mesmo o consumo de álcool muitas vezes entendido como nocivo pela maioria dos participantes e sua família, não é traduzido como abusivo ou dependência, onde o negar a realidade é o melhor refúgio para se viver o vício, que causa euforia e sensação de poder. Porém, para os familiares, o convívio prolongado com o consumidor de álcool faz com que a família ignore a participação deste nas festas e reuniões. Isso se deve a mudança de comportamento apresentada pelo ente após beber a bebida alcoólica, onde este repara a mudança nas relações, mas ao mesmo tempo, não demostra culpa ou arrependimento na ingestão do álcool.

Consequências do consumo de bebida alcoólica. Com o passar do tempo, tanto a família quanto o consumidor sofrem as consequências que esse abuso provoca no ambiente familiar. As brigas constantes, a dificuldade em manter a relação de afeto entre os membros, a existência de agressões e a não aceitação das opiniões do membro familiar que consome álcool pode acabar levando a uma naturalização da violência, como demonstra a esposa de um dos entrevistados quando deixa claro que o agride fisicamente.

[...] Fala demais, agressivo, fica falando coisa que a gente não devia falar, coisa que a gente não quer escu$\operatorname{tar}[\ldots .$.$] da vontade de esmagar e muitas vezes eu esma-$ go. Eu falo também, não fico só escutando, não sou de só de escutar, e de responder, eu até dou nele mesmo (referindo-se a agressão física) [...] (F02- esposa).

O comportamento marcado por agressões físicas e verbais, ou aquele encoberto pela sociedade, pelos padrões estabelecidos, como a permanência da esposa com o marido consumidor nocivo de álcool, mesmo que esteja infeliz e insatisfeita, ajudam a banalização e por consequência a naturalização da violência, dificultando a identificação desta por profissionais, pois, os que a vivenciam não a percebem como uma forma de hostilidade (Sena, Boery, Carvalho, Reis, \& Marques, 2011).

É neste contexto de convivência parental e de manter os padrões sociais a qualquer custo, onde se instala tanto o isolamento do usuário de álcool quanto da própria família. Esse afastamento se dá na tentativa de evitar constrangimentos e o aumento da raiva, uma vez que o comportamento do consu- 
midor exacerba-se em eventos sociais onde há a presença de bebidas com teor alcoólico e há a tendência da sociedade ao preconceito e à exclusão (Filzola et al., 2009).

Ele está sendo excluído da própria família, porque a família deixa de lado por ele beber, e ele mesmo se afasta [...]. As irmãs dele fazem almoço, reúnem os amigos e ele sempre está de fora, e não chamam por ele beber e se tornar um ignorante (F03-mãe).

"Eles têm vergonha, despreza (referência à família). Festa de casamento que não me convidaram, vários lugares" (A02).

Todavia, a exclusão não acontece somente dentro do seio familiar, ocorre inclusive e de forma mais evidente na sociedade como um todo (Moretti-Pires et al., 2011). Alguns entrevistados deixam claro e reconhecem não terem sido aceitos em muitas situações, intensificando a consequência da exclusão ocasionada pelo álcool.

“Tem preconceito sim. Ele já até apanhou por causa disso e não foi uma vez não, por discriminação, porque ninguém aguenta [...]" (F02-esposa).

\footnotetext{
Muitos lugares que eu poderia ter ido, mas não (pausa) acabei não indo, porque outras pessoas não me queriam por causa do álcool. Eu poderia estar lá, mas não fui, as pessoas não me queriam lá [...] Festa de casamento que não me convidaram, vários lugares [...] muitas vezes a pessoa não me convidava por causa do uso. (A02)
}

"Acho que algumas vezes já (pausa longa). Tem algumas vezes que algumas pessoas falam 'o cara bebe, ele não é responsável, não dá para confiar' [...]” (A06).

Apesar dos entrevistados consumidores reconhecerem o fator de exclusão que o álcool motiva, situações que a caracterizam foram difíceis de serem recordadas ou talvez foram até evitadas pelos indivíduos abordados, deixando vaga a resposta e apenas reconhecendo que houve situações exclusivas sem as exemplificar. Enquanto fatores de inclusão foram relacionados apenas festividades e colegas que também frequentam os mesmos estabelecimentos onde consomem álcool.

"[...] um monte de exclusão por causa da cachaça. Tipo assim, não consigo colocar uma situação agora, mas teve bastante (pausa longa), agora não me lembro" (A03).

"Sempre acontece dos amigos saber que a gente bebe, daí eles convidam a gente para ir a churrascos e festa [...]" (A04).

Quando questionados quanto às consequências do álcool, os consumidores relataram reconhecer efeitos físicos e financeiros em suas vidas. No entanto os familiares tiveram dificuldade em relatá-las, talvez pela própria negação de que aquilo se traduza como um problema familiar; talvez pela banalização do consumo que seja rotineiro, ou ainda por tentar preservar a imagem da família, negando para si mesmos e para a sociedade que há consequências.

"Não. Sempre foi bem consciente com as coisas" (F01-esposa).

"Acho que não, porque durante o dia trabalhando ele não bebe, ele só bebe depois que sai do trabalho. Financeira dele, é que o dinheiro que ele poderia poupar ele gasta com bebida, é isso" (F03-mãe).
Com todos, tanto com a família, no trabalho, com os filhos, amigos. Já várias consequências. Do tipo bater o carro, acho que foi duas vezes por causa do álcool. Sem motivo nenhum brigar com algum amigo, por causa do álcool. Esposa, gerar, assim (pausa) discussão, mas também não passou de discussão. Separação, eu me separei de uma, depois a outra separou de mim, tudo por causa da influência do álcool (A02).

“Tive. Porque você está tomando você está gastando. Mas em casa assim não, assim é normal, se faltar em casa eu vou diminuir [...]" (A03).

"Não teve briga nem nada, mas teve financeira. Eu já bati o carro por causa da bebida, bati umas três vezes" (A04).

"A gente gasta um pouquinho de dinheiro a mais [...]" (A06)

A literatura tem mostrado que o consumo de bebidas alcoólicas, quando moderado e quando controlado pode, em geral, trazer benefícios para a saúde cardiovascular, contudo o consumo exagerado deste tem-se mostrado responsável por grande número de acidentes de trânsito e de trabalho, abortos, violência doméstica e psicológica (Filzola et al., Freitas, \& Moraes, 2011; 2009; Labrie, Kenney, Lac, \& Migliuri, 2009; Sena et al., 2011; Silveira, Martins, Soares, Gomide, \& Ronzani, 2011).

As consequências do consumo de álcool na família são várias, além de facilitar a violência, envolve sentimentos de negação do dano ao núcleo familiar, na tentativa de esconder da sociedade e de fugir dos padrões socialmente impostos, o que resulta em diminuição do convívio social para manter a boa imagem familiar (Filzola et al., 2009; Silveira et al., 2011). Do mesmo modo ocorre ainda o estresse, traumas, além do fardo de ter um dependente de álcool e de todos os envolvidos estarem sempre na expectativa e ansiedade de cura do membro familiar que faz uso de álcool (Filzola et al., 2009).

Não obstante, das muitas consequências familiares relatadas pelos entrevistados, o consumidor excessivo de álcool passa por uma sucessão de crises, pois ele tem de conviver com os efeitos físicos do álcool, acidentes de trânsito, constrangimentos, isolamentos, perdas econômicas e sociais. Assim, levando-o muitas vezes a exclusão, não só da família, mas também de toda a rede social que o circunda, evidenciando situações vivenciadas de preconceito com o ato de beber em magnitude.

\section{Considerações finais}

Este estudo coloca em evidência as consequências do abuso de bebida alcoólica, que vão para além do financeiro, afetando os domínios sociais, psicológicos e fisiológicos e tendo impacto negativo no grupo familiar.

As falas dos participantes revelam um grande sofrimento das famílias e usuários devido ao consumo e ao abuso de bebida alcoólica, levando ao desrespeito, violência, sentimentos negativos frente ao familiar que usa, mesmo de forma nociva, e que acaba afetando a todos os membros. Há ainda um afastamento do convívio social, na tentativa da preservação da família e adaptação a uma situação provocada pelo comportamento do membro dependente. 
Percebe-se que mesmo tendo aceitado a condição crônica da doença, vivenciando as frequentes recaídas, a família ainda mantém a esperança de cura, sobriedade e a reinserção do usuário na dinâmica familiar e social. Já o membro consumidor de bebida alcoólica, apesar de negar mudanças de comportamento, em sua maioria, quando os reconhecem sentem um pesar do que aconteceu num passado remoto, aceitando sua dependência como um fator de exclusão do grupo familiar e buscando alternativas de amenizar o consumo.

Ressalta-se ainda a importância de estratégias que busquem a conscientização de toda a população sobre os prejuízos da bebida alcoólica. Porém, a problemática envolvida esbarra em questões estruturais e organizacionais do serviço de saúde, que apesar de identificar a necessidade de políticas públicas voltadas à educação em saúde ainda tem obstáculos elementares do sistema e resistência, muitas vezes por parte dos próprios profissionais que dificultam, não somente o acesso, mas também a integração dessa população abordada com as atividades que envolvem o âmbito da saúde.

Destacam-se as limitações do estudo, que incluíram a realização deste em um único bairro, em uma cidade de interior e a pouca aceitação dos indivíduos para envolvimento familiar nas entrevistas. O que talvez, seja motivo para já considerar o quanto o álcool é estigmatizado, inclusive pelos próprios consumidores, ratificando o que já é sabido na literatura. Justificando os poucos trabalhos encontrados, sobretudo com consumidores nocivos de álcool que não estão ou que não procuraram auxílio profissional por não reconhecerem o vício.

Assim, este estudo visa contribuir para que os profissionais de saúde fiquem atentos ao comportamento das pessoas que consomem bebida alcoólica com frequência, auxiliando a família no enfretamento das consequências geradas, estimulando o indivíduo a admitir o abuso exagerado de álcool e aceitar ajuda profissional.

\section{Referências}

American Psychiatric Association, (2011). Manual diagnóstico e estatístico de transtornos mentais - DSM-V. Porto Alegre: Artmed.

Bardin, L. (2011). Análise de conteúdo. São Paulo: Edições 70.

Berenzon, S., Rebeca, R., Geofrey, M. R., \& Medina-Mora, M. H. (2011). Questões relacionadas ao gênero no diagnóstico e classificação de transtornos por uso de álcool entre pacientes mexicanos que buscam serviços especializados. Revista Brasileira de Psiquiatria, 33(suppl. 1), 109-116. doi: 10.1590/S1516-44462011000500008

Cavarini, M. B., Oliveira, J. B., Kerr-Correa, F., \& Lima, M. C. P. (2012). Expectativas positivas com o uso de álcool e o beber se embriagando: diferenças de gênero em estudo do Projeto GENACIS, São Paulo, Brasil. Cadernos de Saúde Pública, 28(7), 1394-1404. doi: 10.1590/S0102311X2012000700017

Dessen, M. A. (2010). Estudando a família em desenvolvimento: desafios conceituais e teóricos. Psicologia: Ciência e Profissão, 30(spe), 202-219. doi: 10.1590/S1414-98932010000500010

Filzola, C. L. A., Tagliaferro, P., Andrade, A. S., Pavarini, S. C. I., \& Ferreira, N. M. L. A. (2009). Alcoolismo e família: a vivência de mulheres participantes do grupo de autoajuda Al-Anon. Jornal Brasileiro de Psiquiatria, 58(3), 181-186. doi: 10.1590/S0047-20852009000300007
Freitas, I. C. M., \& Moraes, S. A (2011). Dependência de álcool e fatores associados em adultos residentes em Ribeirão Preto, São Paulo, Brasil, 2006: Projeto OBEDIARP. (2011). Cadernos de Saúde Pública, 27(10), 20212031. doi: 10.1590/S0102-311X2011001000015

Goto, J. B., Couto, P. F. M., \& Bastos, J. L. (2013). Revisão sistemática dos estudos epidemiológicos sobre discriminação interpessoal e saúde mental. Cadernos de Saúde Pública, 29(3), 445-459. doi: 10.1590/S0102311X2013000700004

Labrie, J. W., Kenney, S. R., Lac, A., \& Migliuri, S. F. (2009). Differential drinking patterns of family history positive and family history negative first semester college females. Addictive Behaviors, 34(2), 190-196. doi: 10.1016/j.addbeh.2008.10.012

Levisky, D. L. (1998). Adolescência: pelos caminhos da violência, a psicanálise na prática social. São Paulo: Casa do Psicólogo.

Malbergier, A., Cardoso L. R. D., \& Amaral, R. A. (2012). Uso de substâncias na adolescência e problemas familiares. Cadernos de Saúde Pública, 28(4), 678-688. doi: 10.1590/S0102-311X2012000400007

Ministério da Saúde. (2011). Vigitel Brasil 2010: vigilância de fatores de risco e proteção para doenças crônicas por inquérito telefônico. Brasília: Ministério da Saúde.

Monteiro, C. F. S., Dourado, G. O. L., Graça, C. A. G., Júnior, \& Freire, A. K. N. (2011). Relatos de mulheres em uso prejudicial de bebidas alcoólicas. Escola Anna Nery, 15(3), 567-572. doi: 10.1590/S141481452011000300018

Moretti-Pires, R. O., Ferro, S. B. G., Büchele, F., Oliveira, H. M., \& Gonçalves, M. J. F. (2011). Enfermeiro de Saúde da Família na Amazônia: conceitos e manejo na temática do uso de álcool. Revista da Escola de Enfermagem da USP, 45(4), 926-32. doi: 10.1590/S0080-62342011000400019

Organização Mundial da Saúde (2008). Classificação estatística internacional de doenças e problemas relacionados à saúde - CID-10. Recuperado de http:// www.datasus.gov.br/cid10/V2008/cid10.htm

Pimenta, J. A., Filho (2010). Negar é no fundo querer recalcar: notas a partir da leitura do texto Die Verneinung. Revista Estudos Lacanianos, 3(4), p-pp. Recuperado de http://pepsic.bvsalud.org/scielo.php?script=sci_ arttext\&pid=S1983-07692010000100012\&lng=pt\&tlng=pt

Pires, R. O. M., \& Corradi-Webster, C. M. (2011). Adaptação e validação do Alcohol Use Disorder Identification Test (AUDIT) para população ribeirinha do interior da Amazônia, Brasil. (2011). Cadernos de Saúde Pública, 27(3), 497-509. doi:10.1590/S0102 311X2011000300010

Prati, L. E., Couto, M. C. P. P., \& Koller, S. H. (2009). Famílias em vulnerabilidade social: rastreamento de termos utilizados por terapeutas de família. Psicologia: Teoria e Pesquisa, 25(3), 403-408. doi: 10.1590/S010237722009000300014

Santos, A. M., Silva, M. R. S., \& Silva, P. A. (2012). O cotidiano dos filhos que convivem com a mãe alcoolista. Ciência, Cuidado e Saúde, 11(4), 697-703. doi:10.4025/cienccuidsaude.v11i4.16987

Sena, E. L. S., Boery, R. N. S. O., Carvalho, P. A. L., Reis, H. F. T., \& Marques, A. M. N. (2011). Alcoolismo no contexto familiar: um olhar fenomenológico. Texto e Contexto - Enfermagem, 20(2), 310-318. doi: 10.1590/S010407072011000200013

Silva, E. C., \& Guimarães, F. (2007). Resenha: família e drogas: prática e teoria a serviço da prevenção. Psicologia: Teoria e Pesquisa, 23(3), 357-358. doi: 10.1590/S0102-37722007000300016

Silveira, O. S., Martins, L. F., Soares, R. G., Gomide, H. P., \& Ronzani, T. M. (2011). Revisão sistemática da literatura sobre estigma social e alcoolismo. Estudos de Psicologia, 16(2), 131-138. doi: 10.1590/S1413294X2011000200003 
Vargas, D. (2011). Atitudes de estudantes de enfermagem frente questões relacionadas ao álcool, alcoolismo e alcoolista. Acta Paulista de Enfermagem, 24(5), 638-44. doi: 10.1590/S0103-21002011000500007

Williamson, L. (2012). Destigmatizing Alcohol dependence: The requirement for an ethical (not only medical) remedy. American Journal of Public Health, 12(5), e5-e8. doi: 10.2105/AJPH.2011.300629

World Health Organization, (2011). Action needed to reduce health impact of harmful alcohol use. Recuperado de http://www.who.int/mediacentre/ news/releases/2011/alcohol_20110211/en/ 
Ana Patrícia Araújo Torquato Lopes, Mestre em Enfermagem pela Universidade Estadual de Maringá (UEM). Endereço para correspondência: Rua Joaquim Cesário, 74, Bairro Flávio Garcia. Coxim - Mato Grosso do Sul, CEP: 79400-000. Telefone: (67) 99563792 ou (67) 32917198. E-mail: anaptorquato@hotmail.com

Gabriela Schiavon Ganassin, Mestre em Enfermagem pela Universidade Estadual de Maringá (UEM). E-mail: gabriela.s.ganassin@gm

Sonia Silva Marcon, Doutora em Filosofia da Enfermagem pela Universidade Federal de Santa Catarina (UFSC), é professora titular do Departamento de Enfermagem da Universidade Estadual de Maringá (UEM). E-mail: soniasilva.marcon@gmail.comail.com

Maria das Neves Decesaro, Doutora em Enfermagem Fundamental pela Escola de Enfermagem de Ribeirão Preto/Universidade de São Paulo (EERP/USP), é professora adjunta do Departamento de Enfermagem da Universidade Estadual de Maringá (UEM).

E-mail: mndecesaro@uem.br 